\title{
Maxiprocessos criminais, corrupção e mídia: uma análise a partir da operação lava jato
}

\author{
Criminal Maxiprocesses, Corruption and the Media: \\ An Analysis from the Operation Car Wash
}

\section{Raphael Boldt ${ }^{1}$}

Faculdade de Direito de Vitória, Vitória/ES, Brasil

raphaelboldt@hotmail.com

http://lattes.cnpq.br/7059830980608621

http://orcid.org/0000-0002-1625-9856

\begin{abstract}
Resumo: O estudo possui como objetivo compreender em que medida os maxiprocessos, dos quais a Operação Lava Jato é uma referência paradigmática, e os meios de comunicação de massa contribuíram para a transformação do processo penal no Brasil. Desde o método dialético e de uma perspectiva transdisciplinar que assume os aportes teóricos da criminologia crítica, o trabalho será orientado pela seguinte questão: de que forma a articulação entre a Operação Lava Jato e a narrativa jornalística hegemônica sobre a corrupção contribuiu para a ressignificação dos elementos estruturantes do processo penal? A investigação assume como hipótese que a construção simbólica da realidade pela mídia e a ascensão da Lava Jato promoveram a mutação das fontes de legitimação do processo penal brasileiro, cristalizando a crença de que o controle eficiente do crime requer a expansão do poder punitivo e a introdução de novos métodos processuais que restrinjam os direitos e garantias fundamentais, como é o caso da colaboração premiada e de outros institutos vinculados à justiça negocial.
\end{abstract}

1 Pós-Doutorado em Criminologia pela Universität Hamburg (bolsa DAAD). Doutor e Mestre em Direitos e Garantias Fundamentais pela Faculdade de Direito de Vitória (FDV). Estágio doutoral na Johann Wolfgang-Goethe Universität/Frankfurt am Main. Pesquisador visitante junto ao Instituto Max-Planck de História do Direito Europeu. Membro do Grupo de Pesquisa CNPq Direito, Sociedade e Cultura (FDV). Professor nos cursos de Graduação e Pós-Graduação da FDV. Advogado criminalista. 
Palavras-chave: Maxiprocessos; Corrupção; Mídia; Operação Lava Jato; Direitos Fundamentais.

ABSTRACT: The study aims to understand to what extent the maxiprocesses, of which Operation Car Wash is a paradigmatic reference, and the media contributed to the transformation of the criminal process in Brazil. From the dialect method and a transdisciplinary perspective that assumes the theoretical contributions of critical criminology, the work will be guided by the following question: how the articulation between Operation Car Wash and the journalistic narrative about corruption contributed to the resignification of the structuring elements of criminal proceedings? The investigation assumes as a hypothesis that the symbolic construction of reality by the media and the rise of Operation Car Wash promoted the mutation of the sources of legitimization of the Brazilian criminal process, crystallizing the belief that efficient control of crime requires the expansion of punitive power and the introduction of new procedural methods that restrict fundamental rights, as is the case with a leniency deal and other institutes linked to bargained justice.

Keywords: Maxiprocesses; Corruption; Media; Operation Car Wash; Fundamental Rights.

SUMÁRIO: Introdução; 1. Maxiprocessos criminais: a instrumentalização política do processo penal no Brasil; 1.1 A reafirmação da epistemologia inquisitiva e a normalização do subsistema penal de exceção; 2. Discurso midiático e corrosão simbólica do garantismo; 2.10 problema da corrupção: representação da realidade e legitimação do autoritarismo processual; 3. Operação Lava Jato e erosão do processo penal democrático 3.1 A neutralização do sistema de direitos e garantias constitucionais; 3.2 Novas formas de autenticação da verdade: a "inevitabilidade" da colaboração premiada; Considerações finais; Referências.

\section{INTRODUÇÃO}

O sistema de justiça criminal tem passado por transformações profundas no Brasil. A análise dessas alterações pressupõe o estudo dos 
maxiprocessos ou megaprocessos criminais ${ }^{2}$, em especial da Operação Lava Jato, parcialmente responsável pela modificação das representações sociais sobre o direito e o processo penal, bem como da estrutura da justiça criminal no país.

Portanto, o presente estudo possui como objetivo central compreender em que medida a Operação Lava Jato e os meios de comunicação de massa contribuíram para a ressignificação dos elementos estruturantes do processo penal contemporâneo a partir da constituição discursiva da realidade do sistema de justiça criminal brasileiro.

Embora o debate em torno desses temas possua facetas políticas e jurídico-penais, os juristas geralmente limitam-se a esta última, desconsiderando aspectos fundamentais. Assim, desde o método dialético ${ }^{3}$ e de uma perspectiva transdisciplinar que assume os aportes teóricos da criminologia crítica, o trabalho será orientado por algumas questões norteadoras, das quais interessa-nos, em particular, a seguinte: de que forma a articulação entre a Operação Lava Jato e a narrativa jornalística hegemônica contribuiu para a ressignificação dos elementos estruturantes do processo penal no Brasil?

Para responder a essa questão, o percurso investigativo será dividido em três partes. Num primeiro momento analisaremos o fenômeno do "gigantismo processual", considerado por Ferrajoli como resultado da

2 FERRAJOLI, Luigi. Direito e Razão: teoria do garantismo penal. São Paulo: Revista dos Tribunais, 2002, p. 661. Para uma relação dos megaprocessos com o direito de defesa, Cf.: MALAN, Diogo. Megaprocessos criminais e direito de defesa. Revista Brasileira de Ciências Criminais, vol. 159, set. 2019, p. $45-67$.

3 Questionar a verdade absoluta e os próprios argumentos, submeter-se à autocrítica permitindo aberturas transdisciplinares que propiciem o diálogo e exortem à mudança da realidade, premissas que compõem o pensamento dialético e que se adaptam aos objetivos do presente artigo. Nos referimos à "dialética moderna" na qual se inserem os autores da primeira geração da Escola de Frankfurt, que trabalha, implícita ou explicitamente, com as figuras lógicas elementares das antinomias estritas e que assume seu caráter incompleto e inacabado; uma "dialética aberta" que reconhece as persistentes tensões entre teoria e realidade. A respeito da dialética frankfurtiana, Cf.: RITSERT, Jürgen. Themen und Thesen kritischer Gesellschaftstheorie: Ein Kompendium. Weinheim und Basel: Beltz Juventa, 2014, p. 86. 
mutação substancial dos métodos de verificação da verdade e das figuras delituosas ${ }^{4}$. É, sobretudo, no contexto da persecução à criminalidade organizada e aos crimes econômicos que esse modelo obteve êxito em diversos países, inclusive no Brasil.

A segunda parte do artigo destina-se a expor a atuação da mídia na construção do "combate à corrupção" como cerne do imaginário que preside o comportamento dos agentes estatais envolvidos na Operação Lava Jato, capaz de justificar socialmente práticas judiciais arbitrárias, claramente divorciadas dos limites constitucionais e legais.

Por fim, iremos demonstrar como essa "angústia quase apocalíptica" ${ }^{5}$ em relação à corrupção favoreceu a mutação das fontes de legitimação do processo penal contemporâneo, cristalizando a crença de que somente por meio da expansão do poder punitivo e da introdução de novos métodos processuais e técnicas normativas que restrinjam os direitos e garantias fundamentais torna-se possível o controle dos delitos de cariz econômico-financeiro.

Apesar das dificuldades conceituais e das particularidades de cada ordenamento jurídico ${ }^{6}$, o objeto de análise será principalmente a barganha no processo penal e, mais especificamente, a colaboração premiada, instituto que implica na renúncia à defesa, por meio da aceitação do réu à acusação em troca de algum benefício, negociado e pactuado entre as partes ou somente almejado pelo acusado.

4 FERRAJOLI, Luigi. Direito e Razão: teoria do garantismo penal. São Paulo: Revista dos Tribunais, 2002.

5 INGRAO, Christian. Crer e destruir: os intelectuais na máquina de guerra da SS nazista. Rio de Janeiro: Zahar, 2015, p. 31.

6 A respeito, Cf.: LANGER, Máximo. Dos transplantes jurídicos às traduções jurídicas: a globalização do plea bargaining e a tese da americanização do processo penal. DELICTAE: Revista de Estudos Interdisciplinares sobre o Delito, Belo Horizonte, v. 2, n. 3, p. 19-114, 2017. VASCONCELLOS, Vinicius Gomes de; MOELLER, Uriel. Acordos no processo penal alemão: descrição do avanço da barganha da informalidade à regulamentação normativa. Boletín Mexicano de Derecho Comparado, n. 147, septiembre-diciembre de 2016, p. 13-33. 


\section{MAXIPROCESSOS CRIMINAIS: A INSTRUMENTALIZAÇÃO POLÍTICA DO PROCESSO PENAL NO BRASIL}

\subsection{A REAFIRMAÇÃO DA EPISTEMOLOGIA INQUISITIVA E A NORMALIZAÇÃO DO SUBSISTEMA PENAL DE EXCEÇÃO}

A Operação Lava Jato apresenta-se como manifestação do que Ferrajoli denominou "gigantismo processual"', fenômeno que aponta para a expansão pluridimensional do processo penal. Como elemento estrutural do subsistema penal de exceção, o fenômeno dos maxiprocessos se desenvolve em três dimensões distintas: (a) horizontalmente, mediante megainvestigações contra centenas de indivíduos, das quais geralmente decorrem prisões provisórias sem fundamentos aptos a justificá-las, mas extremamente úteis como instrumentos de coerção e obtenção de delações; (b) verticalmente, com a multiplicação da responsabilidade dos investigados e dos réus; (c) temporalmente, por meio do prolongamento excessivo dos processos, violando, no caso brasileiro, a duração razoável do processo e viabilizando a manutenção desmesurada da prisão preventiva, especialmente em virtude da ausência de prazo legal para a sua duração.

A consolidação dos maxiprocessos surge, principalmente, como resultado de dois fatores: (1) transformações experimentadas pelo direito penal contemporâneo, cuja normatividade vem sendo descaracterizada em virtude da debilitação do conceito de bem jurídico e de seu funcionamento como fundamento e limite da legitimidade do direito penal; (2) epistemologia inquisitiva subjacente ao processo penal moderno, responsável pela mutação e ampliação dos métodos de verificação e autenticação da verdade.

Ainda que diversos autores defendam mudanças específicas no âmbito do direito penal, com a relativização da intervenção mínima em relação a algumas áreas, como ocorre, por exemplo, no tocante à macrocriminalidade ${ }^{8}$, a expansão penal no Brasil desconsidera

7 FERRAJOLI, Luigi. Direito e Razão: teoria do garantismo penal. São Paulo: Revista dos Tribunais, 2002, p. 661.

8 Entre outros: BACIGALUPO, Enrique. Derecho Penal Económico. Buenos Aires: Editorial Hamurabi, 2005. TIEDEMANN, Klaus. Manual de Derecho Penal 
aspectos político-criminais estratégicos e assume o endurecimento da legislação e a criminalização como solução para quase todas as mazelas sociais, inclusive para os problemas atinentes à segurança pública, em um claro desvirtuamento das finalidades declaradas das normas penais.

No campo processual, os influxos do modelo processual norte-americano geram algumas modificações no processo penal brasileiro que, apesar das críticas, parecem irreversíveis. Concebido por Schünemann como um simulacro ${ }^{9}$, o processo norte-americano tornou-se a principal referência para as reformas processuais europeias e latino-americanas, não por sua conformidade ao Estado de Direito ou ao sistema de garantias constitucionais, mas justamente por suas debilidades e por otimizar a persecução penal. A proposta de incorporar institutos como o plea bargaining e o acordo de não persecução penal no ordenamento jurídico pátrio, bem como a expansão da colaboração premiada e dos acordos de leniência, reforçam a tendência que aponta para o triunfo do sistema norte-americano.

Para além das objeções a esses institutos e apesar de alguns pontos positivos do modelo adversarial norte-americano, é importante observar que o direito processual brasileiro não deriva da common law, mas remonta a antigas instituições do civil law, o que tende a dificultar o funcionamento de um processo penal reformado e disfuncional do ponto de vista dos valores do Estado de Direito e da tradição jurídica que serve de matriz para o nosso sistema processual.

Apesar de Schünemann sustentar que o modelo adversarial reduz o processo penal ao combate entre adversários, com a eliminação do descobrimento da verdade, no caso de institutos como a colaboração premiada e o acordo de não persecução penal essa crítica deve ser vista com considerável cautela. Na realidade, a atual "americanização do processo" tem contribuído para consolidar os elementos autoritários de um modelo que não foi capaz de romper com a epistemologia inquisitiva subjacente

Económico: Parte General y Especial. Valencia: Tirant lo Blanch, 2010. No Brasil: SCHMIDT, Andrei Zenkner. Direito penal econômico: parte geral. Porto Alegre: Livraria do Advogado, 2015.

9 SCHÜNEMANN, Bernd. Estudos de direito penal, direito processual penal e filosofia do direito. GRECO, Luís (Coord.) São Paulo: Marcial Pons, 2013, p. 243. 
à sua principal fonte de inspiração, a doutrina italiana das décadas de 1920 a 1940 e o Código Rocco, descrito por Alfredo Rocco, ministro da justiça de Mussolini, como "o mais fascista dos códigos".

É importante lembrar que "a dogmática penal sempre é histórica" ${ }^{10}$. Apesar das inúmeras modificações pelas quais passou o Código de Processo Penal brasileiro, o seu núcleo não foi alterado. É justamente no período de sua criação que se torna mais evidente a consonância entre a ciência jurídico-penal e a política. Inexistiu uma fratura com a dogmática penal anterior. A realidade do sistema de justiça criminal demonstra que o processo penal continua a se alimentar das racionalizações de legislações autoritárias. A ideologia do Código de 1941 não apenas se concretizou nos artigos legais, mas também contaminou a doutrina, a jurisprudência, a política criminal e as condutas dos agentes estatais.

Atualmente é perceptível a ressignificação de velhos discursos autoritários. Fala-se em "processo pós-acusatório"11 e "Estado pós-democrático"12, um Estado sem limites rígidos ao exercício do poder. O que se nota, pois, é a clara vinculação da política ao direito por meio da ideologia da segurança nacional e de seus múltiplos processos de redefinição pósConstituição de 1988.

O problema está em algo que os processualistas geralmente não percebem: a busca pela verdade. Ela é um obstáculo epistemológico e político à existência de um autêntico sistema acusatório. Ela não só funda o processo desde o inquérito - forma de exercício do poder que, por meio do judiciário, se tornou um instrumento de autenticação da verdade $^{13}$ - mas continua a atuar como um guia para os atores processuais, justificando a ampliação dos horizontes punitivos e práticas completamente arbitrárias.

10 ZAFFARONI, Eugenio Raul. Doutrina penal nazista: a Dogmática Penal Alemã entre 1933 a 1945. Florianópolis: Tirant lo Blanch, 2019, p. 21.

11 GLOECKNER, Ricardo Jacobsen. Processo penal pós-acusatório? Ressignificações do autoritarismo no processo penal. Revista EMERJ, Rio de Janeiro, v. 18, n. 67, jan - fev. 2015, p. 378-408.

12 CASARA. Rubens. Estado pós-democrático: neo-obscurantismo e gestão dos indesejáveis. Rio de Janeiro: Civilização Brasileira, 2018.

13 FOUCAULT, Michel. A verdade e as formas jurídicas. Rio de Janeiro: Nau Editora, 1999. 
Esta é a hipótese que apresentamos e desenvolvemos em trabalho anterior ${ }^{14}$ : a suposta racionalização do processo, defendida pelo pensamento iluminista e por praticamente toda a doutrina processualista, trata-se, na realidade, de um engodo, ou talvez, um artifício retórico que tem contribuído para a aceitação de um paradigma processual declaradamente laico, mas que se funda em "concepções de mundo e sistemas de referência convencionalmente religiosos e pré-racionais" ${ }^{15}$. Em outras palavras, a ruptura com a lógica inquisitorial e a consequente secularização do processo penal não passam de um mito.

A institucionalização e a preservação da lógica inquisitiva favorecem o quadro de quebra das regras do jogo e a inversão ideológica dos direitos humanos, uma vez que se invoca a tutela dos direitos para negá-los. Nos termos de Ferrajoli, “o Estado de direito é defendido mediante sua negação" ${ }^{16}$. Importante perceber, portanto, a normalização da exceção no tratamento das condutas criminalizadas, com a legitimação externa de práticas judiciárias contrárias à Constituição. O que deveria ser apenas uma disfunção do sistema de justiça criminal tornou-se a regra.

Esse fenômeno amplia o poder jurisdicional e agrava a crise de legalidade do direito penal, autorizando arbítrios e abusos. Com amplo apoio dos meios de comunicação, narcotizados pela falácia de um discurso policialesco e autoritário, a perspectiva garantista do processo penal cede espaço para a blindagem teórica das violações dos direitos fundamentais, revigorando práticas autoritárias.

14 Cf. BOLDT, Raphael. Processo penal e catástrofe: entre as ilusões da razão punitiva e as imagens utópicas abolicionistas. Rio de Janeiro: Lumen Juris, 2018.

15 SCHEERER, Sebastian. Desvantagens e utilidade da criminologia crítica nos tempos de terrorismo. In: AMBOS, Kai; BÖHM, María Laura. (org.). Desenvolvimentos atuais das ciências criminais na Alemanha. Brasília: Gazeta Jurídica, 2013, p. 243-251.

16 FERRAJOLI, Luigi. Direito e Razão: teoria do garantismo penal. São Paulo: Revista dos Tribunais, 2002. 


\section{DISCURSO MIDIÁTICO E CORROSÃO SIMBÓLICA DO GARANTISMO}

\subsection{O PROBLEMA DA CORRUPÇÃO: REPRESENTAÇÃO DA REALIDADE E LEGITIMAÇÃO DO AUTORITARISMO PROCESSUAL ${ }^{17}$}

No livro Crítica da Razão Cínica ${ }^{18}$, o filósofo alemão Peter Sloderdijk inverte a frase de Marx eles não sabem, mas o fazem e afirma: eles sabem o que fazem e continuam a fazê-lo. A crítica à racionalidade cínica expõe o cinismo como uma nova face da ideologia, uma consciência que desvelou os pressupostos que determinavam seu agir "alienado" e ainda assim é capaz de justificar racionalmente tal ação. Para Sloterdijk, o mal -estar na cultura contemporânea adotou uma nova qualidade e agora se manifesta como cinismo universal e difuso. A crítica perdeu o seu poder desmistificador em uma época na qual o cinismo não é mais apenas um problema moral, senão um padrão de racionalidade.

Segundo Sloterdijk, o cinismo abdicou da sua potência crítica e assumiu a "lógica dos senhores", infiltrando-se, assim, na raiz dos totalitarismos modernos. Dominados por uma "falsa consciência ilustrada", professores, juristas, políticos, enfim, indivíduos que deveriam representar os ideais sociais de liberdade, passaram a exercer, cinicamente, o monopólio da mentira. Assim como ocorreu na Alemanha de Sloterdijk durante a República de Weimar, assistimos no Brasil à metamorfose do cinismo. Parafraseando Zizek ao referir-se à ideologia, "sabemos que ela é uma ilusão, mas mesmo assim a queremos"19.

Após a decisão do STF sobre a execução antecipada da pena, a força tarefa da Operação Lava Jato no Paraná declarou, por meio de uma nota, que a decisão do Tribunal está "em dissonância com o sentimento

17 Algumas ideias contidas neste tópico foram apresentadas originalmente em ensaio de nossa autoria intitulado Operação Lava Jato e corrupção: uma crítica da razão cínica, disponível em: https://www.cartacapital.com.br/justica/ operacao-lava-jato-e-corrupcao-uma-critica-da-razao-cinica/.

18 SLOTERDIJK, Peter. Crítica da razão cínica. São Paulo: Estação Liberdade, 2012.

19 ZIZEK, Slavoj. Eles não sabem o que fazem: o sublime objeto da ideologia. Rio de Janeiro: Jorge Zahar, 1990. 
de repúdio à impunidade e com o combate à corrupção, prioridades do país" ${ }^{20}$. Embora o artigo 102 da Constituição Federal afirme que "compete ao Supremo Tribunal Federal, precipuamente, a guarda da Constituição” e seja função institucional do Ministério Público zelar pelo efetivo respeito aos direitos nela assegurados, os membros da força tarefa estabeleceram, arbitrariamente, outras prioridades para o país e suas instituições. Na visão dos procuradores, guardar a Constituição Federal e fiscalizar a aplicação da lei são, portanto, atribuições secundárias diante do combate à corrupção. O equívoco do argumento está justamente em acreditar que só é possível punir tais desvios por meio da violação do texto constitucional. Cinicamente, os direitos e garantias constitucionais são apresentados justamente por quem deveria defendê-los - como obstáculos à persecução penal e ao fim da impunidade.

Essa perspectiva sinaliza para a atual transformação na legitimação do direito e do processo penal. Contra o "inimigo" as regras do jogo podem ser violadas, pouco importando os riscos dessa estratégia para a democracia. Assim, o processo penal, que no Brasil nunca foi acusatório, transformou-se em mero instrumento de condução política. De forma mais geral, as distorções oriundas de maxiprocessos como a Lava Jato tem produzido não apenas o desmantelamento do sistema de direitos e garantias fundamentais, mas a cristalização dos valores pragmáticos da segurança e da eficiência.

A fantasia ideológica garante a imunização da Lava Jato, apresentada diariamente pelos meios de comunicação de massa como símbolo de moralidade e integridade, "a maior investigação de corrupção e lavagem de dinheiro na história do país”. Infelizmente o desinteresse dos juristas pela história das ideias explica porque é tão difícil romper com o passado e tão fácil ressignificá-lo. Mente-se dizendo a verdade. A adesão à narrativa hegemônica sobre a Operação Lava Jato revela que pouco importa se realmente existem violações aos princípios do processo penal e aos direitos e garantias fundamentais. Assume-se simplesmente que os fins justificam os meios.

20 A nota emitida pela força tarefa foi divulgada por inúmeros veículos de comunicação, entre outros: https://oglobo.globo.com/brasil/lava-jato-diz-quedecisao-do-stf-esta-em-dissonancia-com-sentimento-de-repudio-impunidade-24069002. 
O discurso punitivo justifica, inclusive, o autoritarismo e a violência desmedida contra aqueles que se opõem à nova ordem. O senso comum jurídico está presente nas salas de aula, nas salas de audiência, nos tribunais, enfim, em todos os espaços privilegiados que deveriam se destacar pela resistência ao conhecimento pasteurizado, esquematizado, simplificado. Retornando a Sloterdijk, a crítica da razão cínica explicita que os juristas não são marionetes alienadas, mas sabem o que fazem e continuam a fazê-lo.

No Brasil da Operação Lava Jato, a exceção tem sido justamente observar os direitos dos acusados. O direito e o processo penal foram colonizados pelos fins políticos e a narrativa oficial perpetua o que Ferrajoli chamou de "subsistema penal de exceção" ${ }^{21}$. São prisões preventivas decretadas para constranger réus a delatarem, teorias que excepcionam provas ilícitas, relativização das nulidades absolutas, banalização da justiça negocial (em especial da colaboração premiada), conduções coercitivas injustificadas, ampla aceitação de denúncias genéricas, expansão das hipóteses de responsabilidade penal objetiva etc. Tudo se torna legítimo quando a finalidade é erradicar a corrupção.

Mais do que apenas destacar os contornos do pensamento autoritário da justiça brasileira, a Lava Jato expôs a clara vinculação do discurso jurídico dominante à ideologia da segurança nacional. No paradigma de exceção permanente, a luta contra o crime organizado e a corrupção acarretou a perversão substancial do princípio da legalidade. Alguns juízes e membros do Ministério Público sugerem, inclusive, uma coligação inquisitiva em favor da sociedade, dos “cidadãos de bem”. De modo muito semelhante à “Operação Mãos Limpas”, na Itália, são inúmeros os encontros operativos, trocas informais de notícias e conselhos fora dos autos e dos canais processuais.

Presenciamos atualmente o fim do direito penal liberal e a radicalização do sistema inquisitivo. Apesar da notória dificuldade de estabelecer uma definição satisfatória para a corrupção, se a compreendermos como "o abuso de poder condicionado por

21 FERRAJOLI, Luigi. Direito e Razão: teoria do garantismo penal. São Paulo: Revista dos Tribunais, 2002, p. 649. 
vantagens" ${ }^{22}$, como propõem Greco e Teixeira, talvez seja possível concluir que a Operação Lava Jato a incorporou em suas táticas para alcançar um fim socialmente adequado e politicamente útil. Em outras palavras, a Lava Jato rompeu com as regras do Estado de Direito com o objetivo de reprimir os desvios.

Igualmente relevante para a Operação tem sido o papel desempenhado pela imprensa. Como expressa Santoro, a privilegiada posição social dos investigados, a utilização de meios de obtenção de informações tecnologicamente mais avançados e ocultos capazes de devassar a intimidade dos investigados, com a consequente espetacularização do processo, tornaram as "operações" um produto de venda essencial à mídia ${ }^{23}$.

$\mathrm{O}$ acirramento da fragilização dos postulados constitucionais do processo penal democrático por megaprocessos como a Lava Jato vincula-se claramente à atuação dos meios de comunicação, uma vez que estes cumprem o importante papel de "reconstruir os fatos" por intermédio das notícias. Diante da complexidade de casos envolvendo inúmeros réus e crimes sofisticados, tudo precisa ser devidamente e excessivamente simplificado e dramatizado para a população, favorecendo, assim, a superexposição dos suspeitos e acusados, com a promoção de instrumentos de investigação que, combinados, formam um quadro que Neuling chamou de "inquisição por meio da informação" 24 .

No Brasil, a tentação totalitária subjacente ao discurso de "guerra contra o crime” disseminado pela mídia tem autorizado práticas

22 GRECO, Luís; TEIXEIRA, Adriano. Aproximação a uma teoria da corrupção. In: LEITE, Alaor; TEIXEIRA, Adriano (Org.). Crime e política: corrupção, financiamento irregular de partidos políticos, caixa dois eleitoral e enriquecimento ilícito. Rio de Janeiro: FGV Editora, 2017, p. 31-32.

23 SANTORO, Antonio E. R. A imbricação entre maxiprocessos e colaboração premiada: o deslocamento do centro informativo para a fase investigatória na Operação Lava Jato. Revista Brasileira de Direito Processual Penal, Porto Alegre, vol. 6, n. 1, jan./abr. 2020, p. 83.

24 A expressão foi empregada pelo autor no título da obra. Cf.: NEULING, Christian-Alexander. Inquisition durch Information: Medienöffentliche Strafrechtspflege im nichtöffentlichen Ermittlungsverfahren. Beiträge zum Informationsrecht, Band 13. Berlin: Duncker \& Humblot, 2005. 
juridicamente ilegítimas, porém politicamente justificadas. Nota-se, pois, a relevância do papel desempenhado pelos meios de comunicação, uma vez que a ideologia implícita ao discurso dominante funciona como mecanismo de construção da realidade a partir, principalmente, do encobrimento das reais funções dos direitos humanos em uma sociedade democrática e da reafirmação das funções declaradas do sistema penal. Como resultado, verifica-se a "corrosão simbólica do garantismo" 25 , consubstanciada na deslegitimação de práticas comprometidas com a tutela dos direitos fundamentais em virtude da deterioração da teoria no plano discursivo.

Desse panorama complexo podemos extrair algumas breves conclusões. A primeira e mais importante é perceber que a democracia pressupõe, nos termos de João Mauricio Adeodato, a fragmentação do poder, além de certa desconfiança em relação ao caráter humano ${ }^{26}$. As estratégias deliberadas para dificultar o direito de defesa, sobretudo nos processos de corrupção, perpassam a suposta tentativa de tornar mais eficiente a persecução penal. Elas escancaram uma racionalidade que, sob o pretexto de acabar com a criminalidade dos poderosos, propaga o continuísmo de ideias e práticas autoritárias no Brasil.

Por fim, se faz necessário reafirmar o óbvio: este artigo não assume a corrupção como um valor, muito menos desconsidera a relevância de instituições que são pressupostos do Estado Democrático de Direito. Porém, para punir é necessário garantir. Se por um lado seria hipocrisia negar os incontáveis e nocivos casos de corrupção no país, por outro, nunca foi tão importante resistir à generalização do cinismo, uma espécie de mentalidade coletiva. Em tempos de notória instrumentalização da justiça penal para fins políticos e de deterioração dos direitos humanos em prol do "bem comum", torna-se fundamental rejeitar o cinismo da barbárie punitiva que "está passando o Brasil a limpo".

25 BOLDT, Raphael. Criminologia midiática: do discurso punitivo à corrosão simbólica do garantismo. Curitiba: Juruá, 2013, p. 143.

26 ADEODATO, João Maurício. A retórica constitucional (sobre tolerância, direitos humanos e outros fundamentos éticos do direito positivo). São Paulo: Saraiva, 2010, p. 116. 


\section{OPERAÇÃO LAVA JATO E EROSÃO DO PROCESSO PENAL DEMOCRÁTICO}

\subsection{NEUTRALIZAÇÃO DO SISTEMA DE DIREITOS E GARANTIAS CONSTITUCIONAIS}

Apesar de vivermos atualmente em uma sociedade marcada pela sofisticação dos mecanismos de controle social, a descrença nas instituições disciplinadoras por excelência tem contribuído para a expansão do exercício de poder por intermédio dos meios de comunicação de massa, fenômeno chamado por Mathiesen de "sinóptico"27. Com o avanço da tecnologia, não apenas o Estado, mas também os cidadãos passaram a controlar comportamentos desviantes e ampliaram os instrumentos de controle tradicionais.

Diante das expectativas frustradas da maioria no que se refere às funções declaradas da pena privativa de liberdade, a Operação Lava Jato canaliza as demandas sociais irracionais por um modelo de direito penal máximo carente de limites. Apesar de paradoxal, a pretensão de maximizar o poder punitivo estatal para solucionar problemas estruturais do sistema penal - como a gestão seletiva dos comportamentos criminalizados - surge como a única solução possível para coibir os "crimes de colarinho branco" ${ }^{28}$ e promove a consolidação de um sistema de controle penal próprio de Estados totalitários.

Com o aumento do clamor por respostas punitivas mais severas, a intervenção penal torna-se a peça-chave para o controle dos indivíduos que se opõem à ordem estabelecida, passando o direito penal a ser apresentado pela mídia como resposta às aspirações individuais por segurança e instrumento de transformação social. Apesar dos discursos legitimadores da expansão do poder punitivo sinalizarem para a modificação do status quo e a consequente eliminação da corrupção e dos nefastos valores da "velha política brasileira”, o que se percebe é a notória

27 MATHIESEN, Thomas. The viewer society: Michel Foucault's 'Panopticon' revisited. In: Theoretical Criminology. London: SAGE Publications, 1997, p. 12.

28 Para um amplo estudo sobre os crimes de colarinho branco, conferir a pioneira obra: SUTHERLAND, Edwin H. White collar crime - the uncut version. New Haven: Yale University Press, 1983. 
politização do sistema de justiça criminal e sua instrumentalização com vistas a restringir os direitos e garantias individuais, ampliando-se, com isso, os obstáculos à construção da cidadania e os riscos para a gestão dialogal e democrática do poder.

A figura político-discursiva do "combate à corrupção" reconcilia, demagogicamente, partidos políticos conservadores e progressistas e permite o processo de relegitimação midiática do Estado criminalizador. Se por um lado o discurso oficial dos principais meios de comunicação brasileiros alinha-se aos ideais (neo)liberais e propõe a redução do Estado nas searas econômica e social, no que diz respeito às questões atinentes à segurança pública exige um Estado forte e paternalista, contrário aos postulados do direito penal no marco de uma concepção liberal do Estado e do Direito.

Como resultado dessa metamorfose discursiva, observamos a pulverização de políticas públicas direcionadas à concretização dos direitos sociais e a neutralização das bases fundacionais do direito penal clássico, orientado, nas palavras de Vera de Andrade, pela exigência de segurança individual contra a arbitrariedade do poder punitivo e instauração de um regime estrito de legalidade que evite toda incerteza do poder punitivo, promovendo, paralelamente, a sua humanização ${ }^{29}$.

No atual horizonte histórico, a Lava Jato tem operado a partir do "senso comum do positivismo criminológico" ${ }^{30}$, denunciando a defesa dos direitos fundamentais como individualismo exacerbado e conivência com o crime. Sob o pressuposto de resgatar a primazia do social e os direitos da sociedade, os protagonistas da Operação deslocaram o objeto da persecução penal do crime-fato para o criminoso. Para o senso comum, a causa do crime reside no próprio criminoso.

Os estigmas que envolvem o criminoso invertem a programação penal direcionada ao fato (direito penal do fato) e focam no autor-criminoso (direito penal do autor). Entretanto, sob a égide dos megaprocessos e, mais especificamente, da Lava Jato, pouco importa a tentativa

29 ANDRADE, Vera Regina Pereira de. A ilusão da segurança jurídica: do controle da violência à violência do controle penal. Porto Alegre: Livraria do Advogado, 2003, p. 52 e ss.

30 Idem, p. 62. 
de reformar ou ressocializar o indivíduo, prevalecendo, pois, a sua mera incapacitação a partir de uma análise pautada na lógica atuarial, "padrão contemporâneo de racionalidade no sistema de justiça criminal"

É verdade que a busca pelo controle eficiente da criminalidade protagonizada por sujeitos poderosos somente se torna possível mediante a espetacularização dos incidentes e a construção da ideia de que os seus autores se tratam de criminosos incorrigíveis, membros de um sistema estruturalmente corrupto que só pode ser transformado a partir da neutralização dos indivíduos de alto risco. É importante notar que, apesar dos danos causados à sociedade geralmente serem muito superiores a certos ilícitos, como ocorre na maioria dos crimes patrimoniais, os delitos corporativos e aqueles praticados contra a administração pública raramente são abordados com a mesma intensidade pela mídia. Conforme Jewkes, fatores como a complexidade, dificuldade de dramatização e o desenvolvimento a longo prazo dos eventos criminalizados reduzem consideravelmente o interesse dos veículos de comunicação ${ }^{32}$.

Embora não estejamos falando aqui de incapacitação seletiva da underclass, o discurso penal contemporâneo apresenta determinadas categorias como potencialmente perigosas, o que conduz à legitimação de um modelo punitivo que não almeja combater o crime, mas gerenciar grupos. Em outras palavras, sustentada no binômio custo-benefício, a Operação Lava Jato alçou a um novo patamar a gestão econômica ${ }^{33}$ do crime e expôs o compromisso do Estado com os interesses do mercado, fragilizando ainda mais o sistema de direitos e garantias constitucionais.

A Lava Jato obteve legitimidade e amplo apoio da opinião pública brasileira porque conseguiu impor uma narrativa específica sobre o crime e a punição, algo que seria absolutamente impensável sem o apoio da mídia. O mesmo aconteceu na Itália, onde a Operação Mãos Limpas se transformou em um grande espetáculo midiático. Entretanto, um dos grandes problemas é que a "espetacularização" das notícias prejudica a

31 DIETER, Maurício Stegemann. Política criminal atuarial: a criminologia do fim da história. Rio de Janeiro: Revan, 2013, p. 37.

32 JEWKES, Yvonne. Media and Crime. London: Sage Publications, 2004, p. 55.

33 Sobre a abordagem econômica do crime e da punição, conferir a obra fundamental de Gary S. Becker: The Economic Approach to Human Behavior. Chicago: The University of Chicago Press, 1976, p. 39-85. 
capacidade do público discernir entre aquilo que é "fato" e o que é fake. Vivemos a era das fake news, da fake TV. Ficção e realidade confundemse, inclusive no contexto do sistema de justiça criminal, historicamente sustentado por ilusões.

\subsection{NOVAS FORMAS DE AUTENTICAÇÃO DA VERDADE: A "INEVITABILIDADE" DA COLABORAÇÃO PREMIADA}

A Lei dos Crimes Hediondos (Lei 8.072/90) foi a primeira a tratar expressamente da colaboração premiada no Brasil, prevendo no art. $8^{\circ}$, parágrafo único, que "o participante e o associado que denunciar à autoridade o bando ou quadrilha, possibilitando seu desmantelamento, terá a pena reduzida de um a dois terços”. Apesar da entrada em vigor da nova Lei de Organizações Criminosas (Lei 12.850/13) e do regramento específico sobre a colaboração que ela apresenta, o dispositivo da Lei 8.072/90 permanece vigente e válido, juntamente com outras leis que também prevêem a possibilidade de prêmios legais concedidos a agentes que colaborarem com os órgãos da persecução penal, como ocorre, por exemplo, com a Lei de Lavagem de Capitais (Lei 9.613/98, art. $1^{\circ}, \S 5^{\circ}$, com redação dada pela Lei 12.683/12), Lei de Drogas (Lei 11.343/06, art. 41, caput) e Lei de proteção às testemunhas (Lei 9.807/99).

Desde o início da década de 1990 observamos uma tendência à ampliação dos instrumentos de cooperação no direito penal brasileiro, com diferentes incentivos para suspeitos e acusados celebrarem acordos que assegurem maior eficiência às investigações, especialmente em relação aos crimes econômicos e que envolvem organizações criminosas. Assim, a inegável realidade do alargamento dos espaços de negociação no sistema de justiça criminal possui íntima relação com a expansão do fenômeno dos maxiprocessos criminais, geralmente vinculados ao domínio da criminalidade organizada e da persecução à corrupção interna em prol do mercado ${ }^{34}$, e com a mencionada "americanização" do processo penal, parte

34 É importante destacar que alguns instrumentos negociais como a plea bargaining decorrem dos "intensos esforços da OCDE, nominalmente em um sistema de desenvolvimento econômico mundial. Essa composição internacional tem declaradamente um papel de força pensante (think tank), fazedora de regras (rule maker) e de pressão a seus pares (peer pressure)". RODRÍGUEZ, 
de um cenário mais amplo, exposto por Schünemann como a "marcha triunfal do modelo processual penal norte-americano sobre o mundo"35.

Quanto aos influxos do modelo norte-americano no processo penal brasileiro, é fundamental destacar que nos Estados Unidos "o sistema de justiça criminal é agora principalmente um sistema de acordos" ${ }^{36}$, onde as pessoas frequentemente têm negado o direito a um advogado ou a uma defesa consistente e são pressionadas a se declarar culpadas por ameaças de penas inacreditavelmente altas ${ }^{37}$.

Apesar das variações quanto ao objetivo e aos benefícios concedidos pela lei ao colaborador, a colaboração premiada pressupõe a assunção da participação no delito e o fornecimento de informações às autoridades capazes de facilitar a resolução do crime. Importante observar, nesse aspecto, que a regularidade, a legalidade e a voluntariedade da confissão, previstas no art. $4^{\circ}, \S 7^{\circ}$ da Lei $12.850 / 13$, são condições para a homologação do acordo de colaboração pelo magistrado.

No entanto, para além dos aspectos meramente dogmáticos concernentes ao instituto, exaustivamente explicados em importantes trabalhos sobre o tema ${ }^{38}$, é interessante notar alguns problemas oriundos de um paradigma fundado em acordos que, na prática, podem se constituir em um perverso intercâmbio, apto a transformar a acusação em um instrumento de pressão, gerando, com isso, autoacusações falsas, testemunhos caluniosos por conveniência, obstrucionismo ou prevaricações sobre a

Víctor Gabriel. Delação premiada: limites éticos ao Estado. Rio de Janeiro: Forense, 2018, p. 22-23.

35 SCHÜNEMANN, Bernd. Do templo ao mercado? Como a justiça penal aparentemente transforma a teoria econômica do direito em prática, governo em governança e soberania em cooperação. In: SCHÜNEMANN, Bernd. Estudos de direito penal, direito processual penal e filosofia do direito. GRECO, Luís (Coord.) São Paulo: Marcial Pons, 2013.

36 PETEGORSKY, Michael Nasser. Plea Bargaining in the dak: the duty to disclosure exculpatory Brady evidence during plea bargain. Fordham Law Review, Nova York, volume 81, n. 6, 2013, p. 3.602.

37 Sobre o tema, ver: ALEXANDER, Michelle. A nova segregação: racismo e encarceramento em massa. São Paulo: Boitempo, 2017.

38 Entre outros: VASCONCELLOS, Vinicius Gomes de. Colaboração premiada no processo penal. São Paulo: Revista dos Tribunais, 2017. MOURA, Maria Thereza De Assis. BOTTINI, Pierpaolo Cruz. Colaboração premiada. São Paulo: Revista dos Tribunais, 2018. 
defesa, desigualdade de tratamento e insegurança. Nas palavras de Aury Lopes Jr., "o furor negociador da acusação pode levar à perversão burocrática, em que a parte passiva não disposta ao 'acordo' vê o processo penal se transformar em uma complexa e burocrática guerra" ${ }^{39}$.

Na esteira do pensamento de Geraldo Prado, verificamos atualmente a tendência por parte das agências responsáveis pela persecução penal de construírem a verdade sobre os fatos no processo penal, discursivamente, valendo-se de supostas evidências obtidas por meio dos mais variados meios de prova ${ }^{40}$, dos quais se destaca a colaboração premiada, expressão de um modelo de justiça criminal permeado por acordos entre acusador e imputado. Ao tratar da justiça criminal negocial, Vasconcellos aponta os riscos que esse modelo acarreta para o processo penal democrático ${ }^{41}$, concebido, desde a perspectiva garantista, como um instrumento de limitação do poder punitivo estatal.

Ainda que se afirme a necessidade de um acordo voluntário como condição sine qua non para a sua validade e a aplicação dos prêmios legais, devemos analisar o instituto a partir da realidade concreta, situado em um horizonte histórico específico e no contexto perverso e excludente inerente ao funcionamento do sistema penal no capitalismo periférico. A superioridade do acusador público e o poder de transigir tornam as pressões psicológicas e as coações (sobretudo por meio da prisão cautelar) uma prática normal para compelir o acusado a aceitar o acordo e também a "segurança" do mal menor de admitir a culpa, ainda que inexistente.

Nem mesmo as recentes alterações da "Lei Anticrime" (Lei $13.964 / 19)$, no mencionado art. $4^{\circ}, \S 7^{\circ}$, parecem solucionar o problema, pois o cuidado imposto ao juiz no tocante à análise do requisito da "voluntariedade da manifestação de vontade, especialmente nos casos em que

39 LOPES JR. Aury. Prefácio. In: VASCONCELLOS, Vinicius Gomes de. Barganha e justiça criminal negocial: análise das tendências de expansão dos espaços de consenso no processo penal brasileiro. Belo Horizonte: D’Plácido, 2018, p. 14. PRADO, Geraldo. Prova Penal e Sistema de Controles Epistêmicos: a quebra da cadeia de custódia das provas obtidas por métodos ocultos. São Paulo: Marcial Pons, 2014, p. 69.

41 Cf. VASCONCELLOS, Vinicius Gomes de. Barganha e justiça criminal negocial: análise das tendências de expansão dos espaços de consenso no processo penal brasileiro. Belo Horizonte: D’Plácido, 2018. 
o colaborador está ou esteve sob efeito de medidas cautelares”, não evita a mitigação da voluntariedade na celebração de acordos de colaboração premiada com réus presos. Logo, os acusados que se recusam a aceitar a colaboração ou o acordo sobre a pena são considerados incômodos e nocivos, recaindo sobre eles o rigor do "direito penal tradicional", em que qualquer pena acima de quatro anos impede a substituição e, acima de oito anos, impõe o regime inicial fechado.

Além disso, é evidente que a Lei 12.850/13 não estabelece regras suficientes e estamos longe de uma definição clara e precisa acerca dos limites negociais, mesmo com as alterações introduzidas pela Lei 13.964/19. De todo modo, a inovação legislativa exposta no art. $4^{\circ}, \S 16$, amplia as hipóteses de "imprestabilidade das palavras do colaborador" quando isoladamente consideradas, realçando a ideia de que a colaboração premiada não pode, por si só, funcionar como fumus commissi delicti, dependendo de outros elementos de informação e de prova capazes de confirmar suas declarações.

Apesar de algumas posições contrárias, acreditamos que a colaboração premiada apenas ressignificou a estrutura inquisitiva do processo penal brasileiro, pois além de utilizar a coação para obter confissões e um posterior acordo, permanece vinculada à epistemologia da verdade que funda o processo penal moderno e permeia a atuação do intérprete. É importante destacar que a diminuição do risco de condenação para o delator pressupõe a sua confissão e, consequentemente, a renúncia do direito ao silêncio e a submissão ao dever de dizer a verdade. Conforme abordamos em obra diversa ${ }^{42}$, a colaboração premiada assume um modelo epistemológico que deriva do inquérito medieval, em termos foucaultianos, "forma de gestão e exercício de poder" ${ }^{43}$ que configura a principal fonte imaginária dos sistemas processuais da modernidade.

Não se pretende nos estreitos limites deste artigo assumir a tarefa de definir o que é a verdade ou lidar com as inúmeras teorias que tentam explicá-la, senão perceber que a epistemologia da verdade, como

42 Cf. BOLDT, Raphael. Processo penal e catástrofe: entre as ilusões da razão punitiva e as imagens utópicas abolicionistas. Rio de Janeiro: Lumen Juris, 2018.

43 FOUCAULT, Michel. A verdade e as formas jurídicas. Rio de Janeiro: Nau Editora, 1999. 
fonte imaginária do processo penal moderno, tem orientado as práticas judiciais. Desde os primórdios do direito, afirma Janich, é possível notar a invocação de instâncias como a autoridade divina ou a reputação dos ancestrais para nortear a evocação da verdade daquilo que se diz ${ }^{44}$. Para preservar estruturas de poder específicas, a racionalidade jurídico-penal utiliza mitos que são altamente funcionais e importantes para a reprodução acrítica das práticas forenses, forjadas para modelos autoritários/ antigarantistas de sociedade ${ }^{45}$.

Em outras palavras, a aparente "inevitabilidade" da colaboração premiada em casos complexos envolvendo maxiprocessos como a Operação Lava Jato não apenas funciona como mecanismo de fragilização dos direitos e garantias fundamentais, mas reafirma a inquisitorialidade do processo penal brasileiro, cuja matriz provém de uma invenção medieval ocidental desenvolvida a partir de técnicas que se destinavam a pesquisar a verdade no interior da ordem jurídica e que, desde a perspectiva nietzschiana, pode ser compreendido como um mecanismo de produção do conhecimento assentado em relações de poder ${ }^{46}$.

Para além do âmbito judicial, as técnicas de inquérito difundiramse em muitos domínios do saber e se tornaram uma maneira de autenticar a verdade ${ }^{47}$. Desde então, a busca pela verdade tem norteado o trabalho dos atores processuais, ampliando os horizontes de incidência das práticas persecutórias. Por fim, sob a justificativa de solucionar crimes complexos e oferecer uma resposta eficiente à criminalidade crescente e estrutural, em especial àquela de natureza econômica, o que a colaboração premiada fez foi ampliar e sofisticar os aparatos de controle e exercício do poder por meio de acordos que se legitimam na livre e espontânea vontade de partes supostamente iguais. Com o auxílio dos meios de comunicação, o discurso oficial repete incessantemente a relevância da colaboração premiada como meio de prova e obtenção da verdade, impondo um veredicto

44 JANICH, Peter. Was ist Wahrheit? Eine philosophische Einführung. München: Beck, 2000, p. 14.

47 FOUCAULT, Michel. A verdade e as formas jurídicas. Rio de Janeiro: Nau Editora, 1999. 
pretensamente imparcial sobre a imprescindibilidade das delações e a responsabilidade dos delatados.

A ascensão dos megaprocessos criminais produziu, portanto, um produto de venda essencial aos meios de comunicação de massa e esvaziou o processo penal fundado nos fatos para convertê-lo em um instrumento de condução política. Nas palavras de Santoro e Tavares, as colaborações premiadas ganharam um especial relevo nessa nova caracterização do processo penal, cuja utilização como arma política remete ao conceito de Lawfare ${ }^{48}$.

Além de manipular a opinião pública e (re)afirmar tendências no campo do controle penal, a narrativa hegemônica adota uma postura simplória que reduz a corrupção e os problemas da política brasileira à mera discussão sobre valores e a um embate entre mocinhos e vilões. Ao empregar certos signos e se apropriar da verdade, uma das categorias centrais do processo penal, a mídia contribui para a construção da realidade, reorganizando o mundo e alterando as percepções de verdade e sentido da sociedade. De um lado, os agentes da persecução penal são deificados e o exercício do poder punitivo é exaltado, do outro, réus e advogados são transformados em óbice à efetividade da justiça, enquanto os direitos e garantias constitucionais tornam-se meros instrumentos de contaminação da verdade.

A "inevitabilidade" da colaboração com o sistema de justiça criminal por meio do fortalecimento da confissão e da delação de terceiros aniquila, na prática, as pretensões garantistas e confere novos traços ao processo penal moderno, cuja matriz inquisitória inviabiliza propostas reformistas e humanizadoras.

\section{CONSIDERAÇÕES FINAIS}

Mais do que o mero conjunto de atos preordenados a um fim, a teoria processual contemporânea confere ao processo a função de resolução do caso penal por intermédio de uma decisão judicial que

48 Para um amplo estudo do tema, Cf.: SANTORO, Antonio Eduardo Ramires; TAVARES, Natália Lucero Frias. Lawfare brasileiro. Belo Horizonte: D’Plácido, 2019. 
pressupõe a reconstituição da conduta imputada pela acusação, acolhida fundamentadamente, a partir de uma perspectiva de verdade processual proveniente de um processo em contraditório. Ferrajoli, por exemplo, aponta para a necessária conformidade processual às regras do jogo democrático, com a maximização dos direitos fundamentais e a contenção do poder punitivo.

No início deste trabalho destacamos as profundas transformações pelas quais passa atualmente a justiça criminal brasileira, com alterações normativas que legitimam práticas judiciárias cada vez mais questionáveis desde o ponto de vista constitucional. Nesse sentido, a análise dessas alterações pressupõe o estudo dos maxiprocessos ou megaprocessos criminais, em especial da Operação Lava Jato, marco recente para a modificação das representações sociais sobre o direito e o processo penal, bem como da estrutura da justiça criminal no país.

Apresentada oficialmente como "a maior iniciativa de combate à corrupção e lavagem de dinheiro da história do Brasil, [...] com a prisão e a responsabilização de pessoas de grande expressividade política e econômica, e recuperação de valores recordes para os cofres públicos”"49, a Lava Jato promoveu modificações que vão muito além do campo jurídico-penal. Para além da obviedade desse diagnóstico, buscamos compreender em que medida a Operação Lava Jato e os meios de comunicação de massa contribuíram para a ressignificação dos elementos estruturantes do processo penal a partir da constituição discursiva da realidade do sistema de justiça criminal brasileiro.

Chamada por Zaffaroni de "fábrica da realidade" 50 , a mídia tem desempenhado papel fundamental nesse contexto, pois promove a corrosão simbólica do processo penal garantista e a legitimação do poder punitivo, inclusive de seus excessos, por meio de uma narrativa que estabelece o consenso acerca da necessidade de endurecimento do sistema penal contra a "corrupção" estrutural e a elite política e econômica que, supostamente, assume os valores da velha política. Como resultado da

49 Disponível no site do Ministério Público Federal: http://www.mpf.mp.br/ grandes-casos/lava-jato.

50 ZAFFARONI, Eugenio Raul. Em busca das penas perdidas: a perda de legitimidade do sistema penal. Rio de Janeiro: Revan, 2001, p. 127. 
primazia desse discurso, a mobilização dos aparatos punitivos se impõe como única alternativa para a contenção da criminalidade, sobretudo no que se refere aos crimes econômico-financeiros.

A construção simbólica da realidade pelos meios de comunicação de massa e a ascensão de maxiprocessos tem contribuído para a mutação das fontes de legitimação do processo penal, cristalizando a crença de que o controle eficiente do crime requer a expansão do poder punitivo e a introdução de novos métodos processuais e técnicas normativas que restrinjam os direitos e garantias fundamentais, como é o caso da colaboração premiada e de outros institutos vinculados à justiça negocial, institutos que marcam uma tendência aparentemente irreversível, mas ainda carente de uma legislação que delimite as espécies de acordos a partir do modelo processual proposto na Constituição Federal $^{51}$.

No vácuo da perceptível crise de legalidade que se instaurou no Brasil, o processo penal declaradamente deixou de ser concebido e empregado como instrumento para a defesa das liberdades públicas, afastando-se abertamente do seu fundamento ético, ou seja, o compromisso com a proteção da liberdade do inocente. Ao atuar a partir de uma nova racionalidade, o sistema de justiça criminal assumiu definitivamente a lógica de que fins justificam quaisquer meios. Com a erosão dos direitos e garantias fundamentais e a ressignificação pragmática do processo penal, cuja finalidade limita-se atualmente tão somente à cominação de penas, o direito à defesa torna-se irrelevante e a atividade jurisdicional transforma-se em mero exercício de poder, legitimada não mais pela Constituição Federal, mas pelos entusiastas de uma insaciável vontade de punir.

${ }^{51}$ Nesse sentido, mas favoravelmente aos mecanismos consensuais no processo penal: REALE JÚNIOR, Miguel; WUNDERLICH, Alexandre. Justiça negocial e o vazio do projeto anticrime. Boletim IBCCRIM, São Paulo, v. 27, n. 318, p. 6-8, 2019. 


\section{REFERÊNCIAS}

ADEODATO, João Maurício. A retórica constitucional (sobre tolerância, direitos humanos e outros fundamentos éticos do direito positivo). São Paulo: Saraiva, 2010.

ALEXANDER, Michelle. A nova segregação: racismo e encarceramento em massa. São Paulo: Boitempo, 2017.

ANDRADE, Vera Regina Pereira de. A ilusão da segurança jurídica: do controle da violência à violência do controle penal. Porto Alegre: Livraria do Advogado, 2003. BACIGALUPO, Enrique. Derecho Penal Económico. Buenos Aires: Editorial Hamurabi, 2005.

BECKER, Gary S. The Economic Approach to Human Behavior. Chicago: The University of Chicago Press, 1976.

BOLDT, Raphael. Criminologia midiática: do discurso punitivo à corrosão simbólica do garantismo. Curitiba: Juruá, 2013.

BOLDT, Raphael. Processo penal e catástrofe: entre as ilusões da razão punitiva e as imagens utópicas abolicionistas. Rio de Janeiro: Lumen Juris, 2018.

CASARA. Rubens. Estado pós-democrático: neo-obscurantismo e gestão dos indesejáveis. Rio de Janeiro: Civilização Brasileira, 2018.

CASARA, Rubens. Mitologia processual penal. São Paulo: Saraiva, 2015.

DIETER, Maurício Stegemann. Política criminal atuarial: a criminologia do fim da história. Rio de Janeiro: Revan, 2013.

FERRAJOLI, Luigi. Direito e Razão: teoria do garantismo penal. São Paulo: Revista dos Tribunais, 2002.

FOUCAULT, Michel. A verdade e as formas jurídicas. Rio de Janeiro: Nau Editora, 1999.

GLOECKNER, Ricardo Jacobsen. Processo penal pós-acusatório? Ressignificações do autoritarismo no processo penal. Revista EMERJ, Rio de Janeiro, v. 18, n. 67, jan - fev. 2015, p. 378-408.

GRECO, Luís; TEIXEIRA, Adriano. Aproximação a uma teoria da corrupção. In: LEITE, Alaor; TEIXEIRA, Adriano (Org.). Crime e política: corrupção, financiamento irregular de partidos políticos, caixa dois eleitoral e enriquecimento ilícito. Rio de Janeiro: FGV Editora, 2017.

INGRAO, Christian. Crer e destruir: os intelectuais na máquina de guerra da SS nazista. Rio de Janeiro: Zahar, 2015. 
JANICH, Peter. Was ist Wahrheit? Eine philosophische Einführung. München: Beck, 2000.

JEWKES, Yvonne. Media and Crime. London: Sage Publications, 2004.

LANGER, Máximo. Dos transplantes jurídicos às traduções jurídicas: a globalização do plea bargaining e a tese da americanização do processo penal. DELICTAE: Revista de Estudos Interdisciplinares sobre o Delito, Belo Horizonte, v. 2, n. 3, p. 19-114., 2017. https://doi.org/10.24861/2526-5180.v2i3.41

LOPES JR., Aury. Prefácio. In: VASCONCELLOS, Vinicius Gomes de. Barganha e justiça criminal negocial: análise das tendências de expansão dos espaços de consenso no processo penal brasileiro. Belo Horizonte: D’Plácido, 2018.

MALAN, Diogo. Megaprocessos criminais e direito de defesa. Revista Brasileira de Ciências Criminais, vol. 159, Set. 2019, p. 45 - 67.

MATHIESEN, Thomas. The viewer society: Michel Foucault's 'Panopticon' revisited. In: Theoretical Criminology. London: SAGE Publications, 1997. https://doi. org/10.1177/1362480697001002003

MOURA, Maria Thereza De Assis. BOTTINI, Pierpaolo Cruz. Colaboração premiada. São Paulo: Revista dos Tribunais, 2018.

NEULING, Christian-Alexander. Inquisition durch Information: Medienöffentliche Strafrechtspflege im nichtöffentlichen Ermittlungsverfahren. Beiträge zum Informationsrecht, Band 13. Berlin: Duncker \& Humblot, 2005.

NIETZSCHE, Friedrich. Genealogia da moral: uma polêmica. São Paulo: Companhia das Letras, 2009.

PETEGORSKY, Michael Nasser. Plea Bargaining in the dak: the duty to disclosure exculpatory Brady evidence during plea bargain. Fordham Law Review, Nova York, volume 81, n. 6, p. 3599-3650, 2013.

PRADO, Geraldo. Prova Penal e Sistema de Controles Epistêmicos: a quebra da cadeia de custódia das provas obtidas por métodos ocultos. São Paulo: Marcial Pons, 2014.

RITSERT, Jürgen. Themen und Thesen kritischer Gesellschaftstheorie: Ein Kompendium. Weinheim und Basel: Beltz Juventa, 2014.

RODRÍGUEZ, Víctor Gabriel. Delação premiada: limites éticos ao Estado. Rio de Janeiro: Forense, 2018.

SANTORO, Antonio Eduardo Ramires; TAVARES, Natália Lucero Frias. Lawfare brasileiro. Belo Horizonte: Editora D’Plácido, 2019. 
SANTORO, Antonio E. R. A imbricação entre maxiprocessos e colaboração premiada: o deslocamento do centro informativo para a fase investigatória na Operação Lava Jato. Revista Brasileira de Direito Processual Penal, Porto Alegre, vol. 6, n. 1, p. 81-116, jan./abr. 2020. https://doi.org/10.22197/rbdpp.v6i1.333

SCHEERER, Sebastian. Desvantagens e utilidade da criminologia crítica nos tempos de terrorismo. In: AMBOS, Kai; BÖHM, María Laura. (org.). Desenvolvimentos atuais das ciências criminais na Alemanha. Brasília: Gazeta Jurídica, 2013.

SCHMIDT, Andrei Zenkner. Direito penal econômico: parte geral. Porto Alegre: Livraria do Advogado, 2015.

SCHÜNEMANN, Bernd. Estudos de direito penal, direito processual penal e filosofia do direito. GRECO, Luís (Coord.) São Paulo: Marcial Pons, 2013.

SLOTERDIJK, Peter. Crítica da razão cínica. São Paulo: Estação Liberdade, 2012.

SUTHERLAND, Edwin H. White collar crime - the uncut version. New Haven: Yale University Press, 1983.

TIEDEMANN, Klaus. Manual de Derecho Penal Económico: Parte General y Especial. Valencia: Tirant lo Blanch, 2010.

VASCONCELLOS, Vinicius Gomes de; MOELLER, Uriel. Acordos no processo penal alemão: descrição do avanço da barganha da informalidade à regulamentação normativa. Boletín Mexicano de Derecho Comparado, n. 147, septiembre-diciembre de 2016, p. 13-33. https://doi.org/10.22201/iij.24484873e.2016.147.10638

VASCONCELLOS, Vinicius Gomes de. Colaboração premiada no processo penal. São Paulo: Revista dos Tribunais, 2017.

VASCONCELLOS, Vinicius Gomes de. Barganha e justiça criminal negocial: análise das tendências de expansão dos espaços de consenso no processo penal brasileiro. Belo Horizonte: D’Plácido, 2018.

WUNDERLICH, Alexandre. Justiça negocial e o vazio do projeto anticrime. Boletim IBCCRIM, São Paulo, v. 27, n. 318, p. 6-8, 2019.

ZAFFARONI, Eugenio Raul. Doutrina penal nazista: a Dogmática Penal Alemã entre 1933 a 1945. Florianópolis: Tirant lo Blanch, 2019.

ZAFFARONI, Eugenio Raul. Em busca das penas perdidas: a perda de legitimidade do sistema penal. Rio de Janeiro: Revan, 2001.

ZIZEK, Slavoj. Eles não sabem o que fazem: o sublime objeto da ideologia. Rio de Janeiro: Jorge Zahar, 1990. 


\section{Informações adicionais e declarações dos autores (integridade científica)}

Declaração de conflito de interesses (conflict of interest declaration): o autor confirma que não há conflitos de interesse na realização das pesquisas expostas e na redação deste artigo.

Declaração de autoria e especificação das contribuições (declaration of authorship): todas e somente as pessoas que atendem os requisitos de autoria deste artigo estão listadas como autores; todos os coautores se responsabilizam integralmente por este trabalho em sua totalidade.

Declaração de ineditismo e originalidade (declaration of originality): Algumas ideias contidas tópico 2.1 foram apresentadas originalmente no artigo Operação Lava Jato e corrupção: uma crítica da razão cínica, disponível em: https://www.cartacapital. com.br/justica/operacao-lava-jato-e-corrupcao-uma-criticada-razao-cinica/. Fora isso, o autor assegura que o texto aqui publicado não foi divulgado anteriormente em outro meio e que futura republicação somente se realizará com a indicação expressa da referência desta publicação original; também atesta que não há plágio de terceiros ou autoplágio. 
Dados do processo editorial

(http://www.ibraspp.com.br/revista/index.php/RBDPP/about/editorialPolicies)

- Recebido em: 09/05/2020

Equipe editorial envolvida

- Controle preliminar e verificação de plágio:

- Editor-chefe: 1 (VGV) 27/06/2020

- Avaliação 1: 30/06/2020

- Editor-associado: 1 (RO)

- Avaliação 2: 06/07/2020

- Revisores: 4

- Avaliação 3: 13/07/2020

- Avaliação 4: 13/07/2020

- Decisão editorial preliminar: 23/08/2020

- Retorno rodada de correções: 04/09/2020

- Decisão editorial final: 08/09/2020

\section{COMO CITAR ESTE ARTIGO:}

BOLDT, Raphael. Maxiprocessos criminais, corrupção e mídia: uma análise a partir da operação lava jato. Revista Brasileira de Direito Processual Penal, Porto Alegre, vol. 6, n. 3, p. 1209-1237, set./dez. 2020. https://doi.org/10.22197/rbdpp.v6i3.385

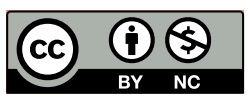

Esta obra está licenciada com uma Licença Creative Commons Atribuição-NãoComercial 4.0 Internacional. 